\title{
Double-balloon tamponade in the management of postpartum hemorrhage: a case series
}

This article was published in the following Dove Press journal:

Therapeutics and Clinical Risk Management

2 August 2014

Number of times this article has been viewed

\author{
Salih Burçin Kavak' \\ Ebru Çelik Kavak ${ }^{2}$ \\ Ismail Demirel ${ }^{3}$ \\ Rașit Ilhan' \\ 'Department of Obstetrics and \\ Gynecology, School of Medicine, Firat \\ Medical Center, Firat University, Elazig, \\ Turkey; ${ }^{2}$ Department of Obstetrics \\ and Gynecology, Special Medical Park \\ Hospital, Elazig, Turkey; ${ }^{3}$ Department \\ of Anesthesiology, School of Medicine, \\ Firat Medical Center, Firat University, \\ Elazig, Turkey
}

\begin{abstract}
To show the efficacy of double-balloon cervical ripening catheter in the management of postpartum hemorrhage originating from the lower segment of the uterus or the upper parts of the vagina.
\end{abstract}

Methods: Patients with intractable bleeding from the lower segment of the uterus and the upper parts of the vagina after Cesarean or vaginal deliveries were treated by double-balloon cervical ripening catheter.

Results: Double-balloon catheter was used in seven patients, and it was properly placed in all of them. No other intervention was needed to control bleeding. Two patients were delivered vaginally, and five patients were delivered by Cesarean section. Length of hospitalization was longer in the vaginal delivery patients (average hospitalization was 12 days in the vaginal delivery patients and 5 days in the Cesarean section patients). The need for blood and blood products transfusion (average of blood and blood products transfusion was $30 \mathrm{U}$ in the vaginal delivery patients and $6 \mathrm{U}$ in the Cesarean patients) was also higher in the vaginal delivery patients.

Conclusion: Although double-balloon cervical ripening catheter is designed for the induction of labor, it can successfully control intractable bleedings from the lower segment of the uterus and the upper parts of the vagina. This procedure can save patients from undergoing more morbid procedures.

Keywords: cesarean section, double-balloon catheter, postpartum hemorrhage, vaginal delivery

\section{Introduction}

Postpartum hemorrhage (PPH) is a common complication of delivery. No consensus about its definition is available; however, blood loss from any part of the genital tract greater than $500 \mathrm{~mL}$ after vaginal delivery and blood loss greater than 1,000 $\mathrm{mL}$ after Cesarean delivery can be classified as PPH. ${ }^{1}$

The cause of hemorrhage must be distinguished correctly to decide the treatment method. Uterine atony, placenta retention, and lacerations of the genital tractus are the most common causes. ${ }^{2}$ As soon as the PPH is observed, treatment options should be applied step by step. If medical treatment fails, conservative methods or surgery are indicated.

The morbidity and mortality of surgical methods are high; therefore, new conservative methods are developed to control the bleeding, including balloon tamponate and arterial embolization. These conservative methods are very important, because most of the intractable bleedings can be successfully treated and hysterectomy can be avoided. ${ }^{3}$ These methods are also more important especially for patients who wish to preserve their fertility.
Correspondence: Salih Burcin Kava Medical Center, Department Obstetrics and Gynecology 23100 , Elazig, Turkey

Tel +9042423335552124

Fax +904242379l 38

Email burcinkavak@gmail.com
Therapeutics and Clinical Risk Management 20I4:10 615-620 
Different types of balloons are used to make the uterine tamponade, according to the cause of PPH. After the delivery of the baby and the placenta, contraction of muscle fibers seals the blood vessels. Because of the low density of muscle fibers in the cervix, control of the bleeding can be more difficult. A balloon exerting pressure from both sides may be more efficient to control bleeding from the lower parts of the uterus.

We herein report a serious case of PPH, originating from the lower segments of the uterus and upper parts of the vagina that was successfully controlled with a doubleballoon catheter.

\section{Materials and methods}

Cases with PPH that were unresponsive to medical treatment were managed with the cervical ripening balloon catheter in Firat University, Faculty of Medicine, Department of Obstetrics and Gynecology, between January 2012August 2013. In this period, 2,164 deliveries occured. Their records were analyzed retrospectively. In the statistical analysis of the data, SPSS 21.0 program (IBM Corporation, Armonk, NY, USA) and descriptive statistics were used. The adopted protocol was approved by the hospital research and ethics committee.

Bleeding of more than $1,000 \mathrm{~mL}$ that is unresponsive to routine management is named $\mathrm{PPH}$. There were two groups of patients. The first group included patients who underwent vaginal delivery and showed uncontrolled bleeding from the cervix and upper parts of the vagina. The second group included patients who underwent a Cesarean section due to placenta previa and showed intractable bleeding from the lower segments of the uterus that was resistant to medical treatment. The lower segment remained floppy and not contracted. Diagnosis of placenta previa was confirmed before the operations by transvaginal ultrasound. In the vaginal delivery group, patients were referred from other hospitals with massive bleeding and a near collapse of the circulation after delivery. They were immediately taken to the operating room. Blood circulation and oxygenation were restored. Uterotonics were continued; the uterus was contracted. A pelvic examination was done under general anesthesia, and lacerations were repaired, if possible. Bleeding continued even from the beds of the suture, or suture could not be applied because of the fragile and edematous consistency of the tissues. We decided to apply a double-balloon cervical ripening catheter made of silicone material (maximum capacity $80 \mathrm{~mL}$, tested top capacity $250 \mathrm{~mL}$; Cook Medical, Bloomington, IN, USA,) to control bleeding (Figure 1).

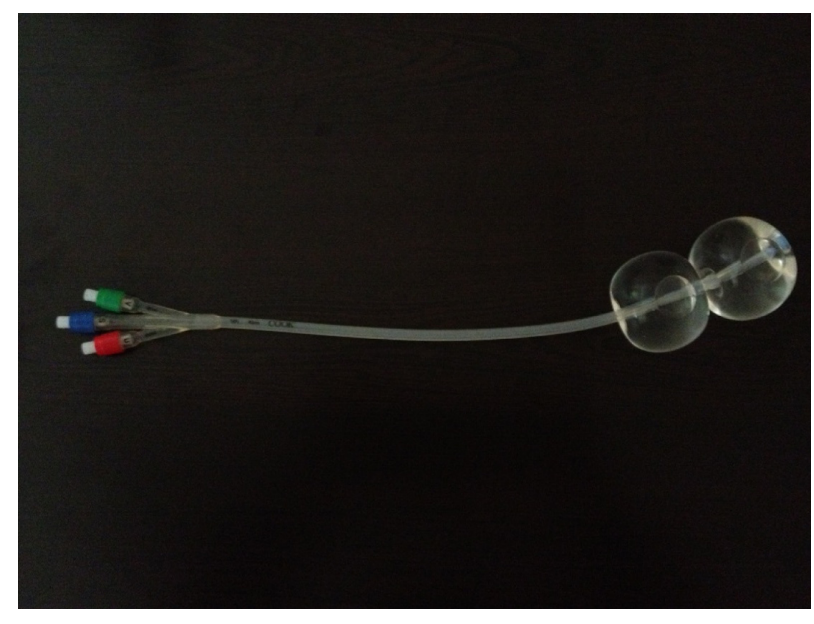

Figure I Cervical ripening catheter.

Ring forceps were used to insert the catheter under direct examination of the cervix. The uterine portion of the balloon was inflated with an $80-110 \mathrm{~mL}$ saline solution. Then, a gentle traction was applied to fit the balloon firmly to the cervical portion of the uterus. The vaginal portion was then inflated with another $80 \mathrm{~mL}$ (Figure 2). The position of the balloons was reevaluated by ultrasonography. In the Cesarean section, the catheter was also inserted vaginally and, after the repair of the uterine incision by using polyglactic acid No 1-0 (Laktasorb, Boz, Istanbul, Turkey), it was inflated by an

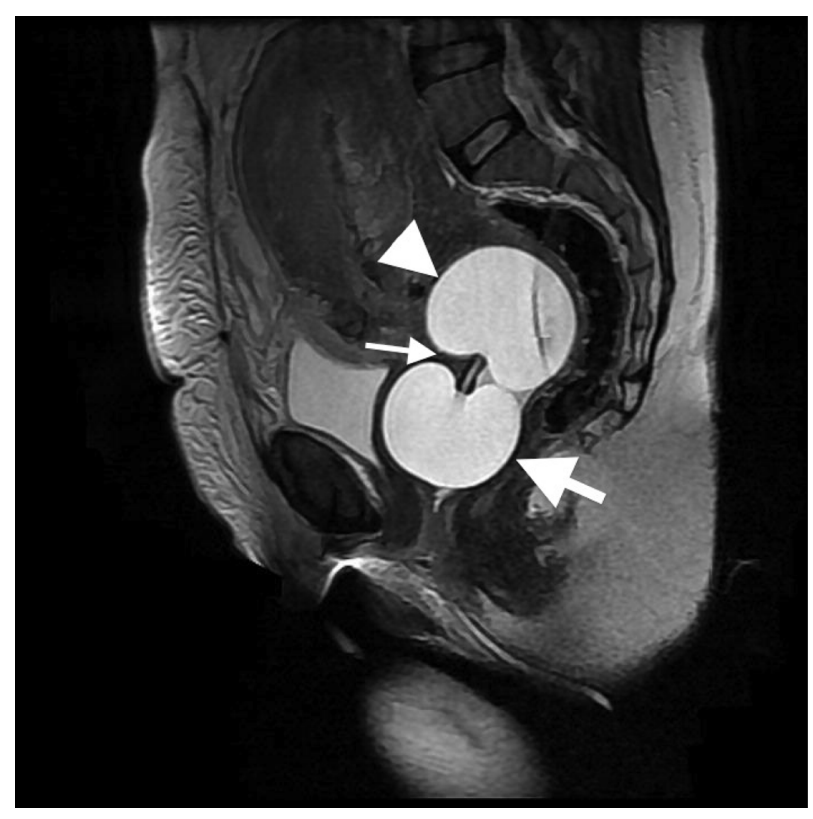

Figure $2 \mathrm{MRI}$ image of cervical ripening catheter in Cesarean section patient. Notes: Inflated cervical ripening balloon involving cervix and proximal vagina. Sagittal T2-weighted MRI demonstrates inflated cervical ripening balloon transversing internal cervical os (thin arrow). Proximal portion of inflated balloon (arrowhead) is localized in the cervix. Distal portion of the balloon (thick arrow) is localized in vagina. Abbreviation: MRI, magnetic resonance imaging. 
assistant vaginally in the same manner. All of the catheters were placed successfully, and in all of the patients, the balloon tamponate worked well.

A marked decrease of the bleeding was observed before the end of the operation. The balloon tamponates were kept inflated for 2 days with careful monitoring of the vital signs and bleeding. The balloons were deflated gradually at a rate of $40 \mathrm{~mL}$ for each balloon every hour; blood leakage was controlled by pads during the deflation period. Broad spectrum antibiotics were given for five days to all patients.

In the Cesarean section group, $5 \mathrm{U} / \mathrm{mL}$ oxytocin (Synpitan forte $^{\circledR}$ ampule, 5 IU; Deva, Istanbul, Turkey) was given as a bolus, following the delivery of the fetus and $0.5 \mathrm{mg}$ methyl ergonovine maleate (Methergine ${ }^{\circledR}$ ampule, $0.2 \mathrm{mg}$; Sandoz Inc., Wilson, NC, USA) was administered as a bolus, following the delivery of the placenta. Also, $20 \mathrm{U} / \mathrm{L}$ of oxytocin was infused in a $1 \mathrm{~L}$ solution and then given as $250 \mathrm{~mL} /$ hour in all patients during the operation and in the first 6 hours postoperatively. Also, $600 \mu \mathrm{g}$ rectal misoprostol was administered to control bleeding. The urine flow and vital signs were recorded every 15 minutes for the first 2 hours and every hour for the other 6 hours. Methylergonovine maleate was given every 8 hours in all patients except the one with preeclampsia.

The postoperative blood loss was calculated by weighing the pads used by the patients, and no major bleeding was detected. Descriptive statistics were used.

The age of the patients, gestational age, mode of delivery, gravidity, parity, birth weight, preoperative and postoperative hemoglobin and hematocrit values, the amount of transfusions of blood and blood products, risk factors for PPH, length of hospitalization, and adverse events are shown in Table 1.

\section{Results}

A double-balloon catheter was used in seven patients, and it was properly placed in all of them. Bleeding was successfully controlled, and no other intervention was needed. None of the patients had placental invasion anomalies. Preeclampsia was present in one of the patients, and massive bleeding caused a coagulation abnormality in one of the patients. These two patients were delivered vaginally. No other systemic or medical disease was present.

The median age of the patients was 30 with a range of 16-41 years old. Gestational age was between 35-39 weeks; median gestational age was 37 weeks. Two patients were nulliparous, and five were multiparous. Five of the PPH followed Cesarean delivery, and the other two followed vaginal delivery. Birth weight ranged between 2,520-4,160 g; median birth weight was $3,080 \mathrm{~g}$. No congenital anomaly was present. All of the patients needed transfusions, but it was much more in the vaginal delivery patients transferred from other centers after delivery. In one patient, disseminated intravascular coagulation occured. She was taken to the intensive care unit after the operation and was monitored in this unit for 5 days.

The average blood/blood products' transfusion amount was $30 \mathrm{U}$ in the vaginal delivery patients and $6 \mathrm{U}$ in the Cesarean section patients. The average length of hospitalization was

Table I Obstetric and clinical characteristics of the cases

\begin{tabular}{|c|c|c|c|c|c|c|c|}
\hline Parameters & Case I & Case 2 & Case 3 & Case 4 & Case 5 & Case 6 & Case 7 \\
\hline $\begin{array}{l}\text { Maternal age (year)/ } \\
\text { gestational age (week) }\end{array}$ & $41 / 39$ & $16 / 38$ & $34 / 35$ & $30 / 37$ & $35 / 36$ & $29 / 37$ & $28 / 36$ \\
\hline $\begin{array}{l}\mathrm{G} \text { (number)/P (number)/ } \\
\mathrm{A} \text { (number) }\end{array}$ & $4 / 3 / 0$ & $1 / 0 / 0$ & $3 / 2 / 0$ & $8 / 1 / 6$ & $2 / 0 / 1$ & $3 / 2 / 0$ & $2 / 1 / 0$ \\
\hline Risk factor & $\begin{array}{l}\text { Advanced } \\
\text { maternal age }\end{array}$ & Preeclampsia & $\begin{array}{l}\text { Placenta previa } \\
\text { totalis }\end{array}$ & $\begin{array}{l}\text { Placenta previa } \\
\text { totalis }\end{array}$ & $\begin{array}{l}\text { Placenta previa } \\
\text { totalis }\end{array}$ & $\begin{array}{l}\text { Placenta previa } \\
\text { totalis }\end{array}$ & $\begin{array}{l}\text { Placenta previa } \\
\text { totalis }\end{array}$ \\
\hline Mode of delivery & Vaginal & Vaginal & $\begin{array}{l}\text { Cesarean } \\
\text { section }\end{array}$ & $\begin{array}{l}\text { Cesarean } \\
\text { section }\end{array}$ & $\begin{array}{l}\text { Cesarean } \\
\text { section }\end{array}$ & $\begin{array}{l}\text { Cesarean } \\
\text { section }\end{array}$ & $\begin{array}{l}\text { Cesarean } \\
\text { section }\end{array}$ \\
\hline Weight of baby (gram) & 3,200 & 3,000 & 2,520 & 4,160 & 3,150 & 3,080 & 2,950 \\
\hline Preoperative Hb (g/dL)/Htc (\%) & $8.4 / 24.6$ & $8.1 / 25.3$ & $7.3 / 23.6$ & 13.1/37.4 & I3.4/37.6 & $12.1 / 35.3$ & II.4/33.I \\
\hline Postoperative I day & $7.4 / 21.1$ & $7.2 / 20.3$ & $9.1 / 26.4$ & $10.1 / 31.2$ & II.6/33.2 & $|0.1 / 3| .2$ & $9.3 / 27.4$ \\
\hline $\begin{array}{l}\text { Postoperative } 3 \text { day } \mathrm{Hb}(\mathrm{g} / \mathrm{dL}) / \\
\text { Htc }(\%)\end{array}$ & $8.9 / 25.2$ & II.I/32.4 & $8.8 / 26.3$ & $9.3 / 27.5$ & $9.8 / 30.1$ & $9.8 / 27.6$ & $9.1 / 26.0$ \\
\hline Red cell concentrate (unit) & 20 & 7 & 3 & 3 & 3 & 3 & 3 \\
\hline FFP (unit) & 20 & 7 & 3 & 3 & 2 & 3 & 3 \\
\hline Whole blood (unit) & 6 & - & I & - & - & - & - \\
\hline Adverse event & DIC & - & - & - & - & - & - \\
\hline Length of hospitalization (days) & 17 & 7 & 6 & 4 & 5 & 4 & 4 \\
\hline
\end{tabular}

Abbreviations: G, gravida; P, parity; A, abortus; Hb, hemoglobin; Htc, hematocrit; FFP, fresh frozen plasma; DIC, disseminated intravascular coagulation. 
12 days in the vaginal delivery patients and 5 days in the Cesarean section patients.

The cases of patients who were bleeding after vaginal delivery were referred from another hospital. One lost consciousness; the other one was confused at admittance. Blood pressure could not be taken. The pulse was thready in the first one and blood pressure was $50 / 40 \mathrm{mmHg}$ and pulse was $124 /$ minutes in the second one.

The other five patients were referred to our hospital with the diagnosis of placenta previa totalis. Two patients had two cesarean section history, the other two patients had one cesarean section and the last patient was nulliparous. All of these five patients underwent a Cesarean section and, after the removal of placenta, bleeding continued from the placental bed. We applied the double-balloon catheter to all and inflated the uterine part with a $0.9 \%$ saline solution, ranging from $80-110 \mathrm{~mL}$ and the vaginal part with $80 \mathrm{~mL}$, since the contraction of the uterus was sufficient. The uterine portion of the double balloon successfully filled the lower segment of the uterus. The hemodynamic status of the patients in the Cesarean section patients did not deteriorate, because balloons were applied in a short time.

\section{Discussion}

After the delivery, the muscles of all parts of the uterus contract rapidly to limit bleeding. Some deliveries can be complicated with life-threatening heavy bleeding if the muscles of any part of the uterus - more commonly the cervix or the whole uterus - do not contract early, rapidly, and strongly enough. Any laceration in the genital tractus also causes such a massive bleeding. Maternal mortality due to PPH is about 100 times higher in resource-poor countries than in resource-rich ones. ${ }^{4}$

Delivery is a process that occurs in every part of the world. It is not possible for a country to gather all the deliveries to special well-equipped centers. Since it is known that etiologies causing PPH in the first 24 hours of delivery cause greater blood loss and morbidity, $\mathrm{PPH}$ must be treated rapidly and - if possible - in the same place as delivery without transfer of the patient. ${ }^{5}$

Because of these reasons, measures that are safe, effective, easily applicable in every unit are very important in the control of PPH. In the past, when uterine massage, administration of uterotonics, curettage and repair of lacerations failed to control massive bleeding, surgical interventions including laparotomy with uterine, utero-ovarian or hypogastric artery ligation, or even hysterectomy were considered. But all these surgical approaches have some morbidities and also need an experienced team and equipment. Hysterectomy is a traumatic option to control bleeding in women who desire to preserve their fertility. So other conservative treatment options, including intrauterine tamponate and uterine artery embolization, have been developed. Although uterine artery embolization is an important modality in the management of PPH and can avoid patients undergoing surgery, it needs equipment and an experienced team.

Uterine tamponate can be applied by balloons. Balloons are inflated to a volume at which it can exert a pressure that is greater than the systemic arterial pressure to uterine wall. It is believed that pressure greater than systemic arterial pressure applied to the uterine wall by the inflated balloon is the mechanism of controlling the hemorrhage. This pressure can be achieved by inflating different balloons by different volumes. ${ }^{6}$

Balloon tamponates in general are procedures that can be applied in the delivery room even by inexperienced operators or midwives. This makes it an important step in the treatment of PPH. It is a safe procedure, and its effect starts as soon as the balloon is inflated. By stopping the hemorrhage promptly, consumptive coagulopathy can be inhibited. This procedure is less invasive than surgical intervention. It can be available in all maternal wards. The availability of the application of the balloon tamponate in the delivery room is very important, because a patient with uncontrolled bleeding cannot be transferred to another center; transfer can make the prognosis worse. ${ }^{7}$

In our study, two cases were transferred after delivery from other centers in our city and their hemodynamic status was unstable at the arrival to our hospital. The need for blood transfusion and the length of hospitalization were longer in these patients. Even in cases with failure, the balloon can also temporarily tamponate the bleeding sites and give the chance of transfer without deterioration of the patient. Laparotomy and hysterectomy can be avoided in many cases.

Different types of balloon tamponates have been used in the last decades to control postpartum hemorrhage, such as the Sengstaken-Blakemore tube, Foley catheter, Rusch catheter, Bakri catheter, or the simple Foley condom. ${ }^{8}$ Success of the balloon tamponate also differs according to the cause of the PPH.

In one study, the catheter placement controlled $\mathrm{PPH}$ originating from uterine atony in $100 \%$ of cases, but it was successful in only $80 \%$ of patients with retained placenta. ${ }^{9}$ In another study, the Bakri balloon tamponate was used to control PPH due to a cervical rupture where the surgical repair did not work. The Bakri balloon was either inserted 
into the lower uterine segment or the vagina. It worked well in six patients among seven, and bilateral artery ligation was needed in one case. ${ }^{10}$

The success rate of the balloon tamponate varies between $77.5 \%-88.8 \%$. This means that approximately among five PPH cases, four can be treated by balloons without undergoing a surgical intervention that has a high morbidity rate. Balloon tamponate can also effectively control bleeding in the cases of placenta accreta, amniotic fluid embolism, septic shock with disseminated intravascular coagulation, and retained placenta. ${ }^{9}$

In the literature, the double-balloon cervical ripening catheter was successfully used to control severe postabortion hemorrhage. ${ }^{11}$ Since maternal mortality is more common in poor countries, such conventional methods that do not need well-equipped hospitals and an experienced team become more important. We believe that by widely and effectively using these methods, maternal mortality can be reduced to a great extent. All the health care staff - including midwives must be aware of the benefits of these balloon catheters and must be able to use them. Special balloons must be designed and distributed to all delivery units all over the world.

The ideal balloon must be flexible, soft, and of a nontraumatic consistency to reduce the risk of perforation. Its application must be easy, so that it can be used by all operators. It must be quickly applied, because a few minutes of lost time may cause prominent blood loss. It must be cheap to be widely usable. It must have a drainage part to calculate correctly the blood loss and to prevent blood collection inside the uterine cavity. Direct visualization of the blood loss also helps us to determine the patients in which the procedure fails. Its shape must be compatible to the shape of the application area.

The only known contraindication of the balloon is postpartum infection. In patients with a rubber/latex allergy, the balloon must be chosen accordingly. The application of the balloon tamponate can be unsuccessful in some cases due to different causes, such as the obstruction of the cervix by leiomyoma. ${ }^{9}$ Few studies report difficulties or failures in using the balloons. Some of these failures may be interpreted as complications of placement. ${ }^{9,12}$ The potential advantage of this double-balloon cervical ripening catheter probably originates from the pressure applied from both sides of the cervix. It can also apply pressure to the upper parts of the vaginal wall.

We first used this balloon in a PPH patient who underwent Cesarean section due to placenta previa, and the Bakri balloon could not be passed from the cervix because of its large diameter. After the observation of its efficacy, we decided to try it in other cases. It worked well in all patients, and no other interventions were needed. We believe that the double-balloon tamponate can effectively control bleeding that originates from the lower parts of the uterus and the upper parts of the vagina. We advise the usage of the double-balloon cervical ripening catheter to stop bleeding from the lower parts of the uterus, but the Bakri balloon is more appropriate for uterine atony due to its large diameter. Also, the double-balloon catheter can be preferred - as in our first case - when the cervix is so small that the Bakri balloon cannot be inserted from the cervix. By sharing our experiences all over the world about the different balloon types, we believe that the ideal balloon can be designed more easily, and the operators can be encouraged to use them before performing a surgical procedure in $\mathrm{PPH}$ resulting from different causes.

One restrictive property of our study was the low number of cases. Further studies must be made with a high number of patients and the best volume of balloon inflation required to stop hemorrhage, the most appropriate duration of application and the type of balloon for different indications must be determined.

\section{Disclosure}

The authors report no conflicts of interest in this work.

\section{References}

1. World Health Organization. Who Recommendations for the Prevention and Treatment of Postpartum Haemorrhage. Geneva: World Health Organization; 2012.

2. Dildy GA. Postpartum hemorrhage: new management options. Clin Obstet Gynecol. 2002;45(2):330-344.

3. Giambattista E, Ossola MW, Duiella SF, et al. Predicting factors for emergency peripartum hysterectomy in women with placenta previa. Arch Gynecol Obstet. 2012;285(4):901-906.

4. Mousa HA, Alfirevic Z. Treatment for primary postpartum haemorrhage [review]. Cochrane Database Syst Rev. 2007;1:CD003249.

5. Dildy GA,Clark SL. Postpartum hemorrhage. Contemp Ob Gyn. 1993 38: 21-29.

6. Condous GS, Arulkumaran S, Symonds I, Chapman R, Sinha A, Razvi K. The "tamponade test" in the management of massive postpartum hemorrhage. Obstet Gynecol. 2003;101(4):767-772.

7. Kavak SB, Korkut B, Kavak E. Investigation of patients who underwent emergency peripartum hysterectomy: 3 year experience. Firat University Medical Journal of Health Sciences. 2012;26:35-38. Available from: tip.fusabil.org/pdf.php3?id=839. Accessed July 24, 2104.

8. Georgiou C. Balloon tamponade in the management of postpartum haemorrhage: a review. BJOG. 2009;116(6):748-757.

9. Dabelea V, Schultze PM, McDuffie RS Jr. Intrauterine balloon tamponade in the management of postpartum hemorrhage. Am J Perinatol. 2007;24(6):359-364.

10. Grönvall M, Tikkanen M, Tallberg E, Paavonen J, Stefanovic V. Use of Bakri balloon tamponade in the treatment of postpartum hemorrhage: a series of 50 cases from a tertiary teaching hospital. Acta Obstet Gynecol Scand. 2013;92(4):433-438. 
11. Tsui KH, Lin LT, Yu KJ, et al. Double-balloon cervical ripening catheter works well as an intrauterine balloon tamponade in post-abortion massive hemorrhage. Taiwan J Obstet Gynecol. 2012;51(3):426-429.
12. Seror J, Allouche C, Elhaik S. Use of Sengstaken-Blakemore tube in massive postpartum hemorrhage: a series of 17 cases. Acta Obstet Gynecol Scand. 2005;84(7):660-664.

\section{Publish your work in this journal}

Therapeutics and Clinical Risk Management is an international, peerreviewed journal of clinical therapeutics and risk management, focusing on concise rapid reporting of clinical studies in all therapeutic areas, outcomes, safety, and programs for the effective, safe, and sustained use of medicines. This journal is indexed on PubMed Central, CAS,

EMBase, Scopus and the Elsevier Bibliographic databases. The manuscript management system is completely online and includes a very quick and fair peer-review system, which is all easy to use. Visit http://www.dovepress.com/testimonials.php to read real quotes from published authors.

Submit your manuscript here: http://www.dovepress.com/therapeutics-and-clinical-risk-management-journal 